\title{
Teachers' perception of struggling students in the orthodox Jewish community
}

\author{
E. Dovid Bak* \\ Lakewood Community Services Corp., USA
}

\begin{abstract}
This study looks at teachers' perception of the emotional struggles of students in their classrooms within one Orthodox Jewish Community. Seventeen teachers within one school were surveyed using a 29 question Likert scale instrument. It was hypothesized that while stigma of mental illness in the Orthodox community may have decreased over time, misunderstanding of mental illness and cultural biases continue to prevent children from receiving the maximum help possible. The majority of respondents reported that between $11-20 \%$ of their students were struggling with some form of emotional/behavioral problem. Attribution was primarily linked to poor parenting, a lack of coping skills, and inborn personality rather than to bullying and abuse.

These findings suggests that cultural stigma and teachers' lack of preparedness in understanding the full range of their children's emotional needs may be an issue for the educational system. Potential solutions would include the development, with input from school administrators, teachers and social workers, of a comprehensive teacher-training program. This intensive training would go beyond classroom management and teaching methods. Its focus would be to educate teachers in child development, and a basic understanding of child psychopathology. Further research is needed to determine if the findings of this study are reflective of the larger Orthodox Jewish community.
\end{abstract}

\section{Introduction}

With the growing awareness in the Unites States of the tremendous burden and difficulty mental illness places upon individuals, families and communities, in 1999 the Surgeon General issued its first-ever report on the nation's mental health [1]. In it the Surgeon General stated that:

Stigma must be overcome. Research that will continue to yield increasingly effective treatments for mental disorders promises to be an effective antidote. When people understand that mental disorders are not the result of moral failings or limited will power, but are legitimate illnesses that are responsive to specific treatments, much of the negative stereotyping may dissipate (p. 9).

Since that time there have been a number of studies with some showing a decrease in the public's perception of mental illness while still others shown no such improvement [2]. However among certain religious groups there still exists a fair amount of stigma which prevents many from seeking help. Pirutinsky et al. [3] found that the shift to and inclusion of medical causes as it relates to mental illness while possibly decreasing stigmatization across the United States actually brought about an increase among Orthodox Jews. Additionally, as the authors noted, the nature of the study may have excluded the more traditional subgroups of Ultra-Orthodox Jews where it is possible that even higher levels of stigmatization may occur.

The purpose of this study is to examine one Ultra-Orthodox community to determine the degree to which stigma may play a role in preventing parents and teachers from identifying certain emotional/ behavioral problems that may negatively impact the functioning of children in the classroom setting. It is hypothesized that while stigma of mental illness in the community may have decreased, a lack of basic understanding of mental illness and cultural biases prevent children from receiving the maximum help possible. This paper will endeavor to show the teachers' perceptions regarding the prevalence of struggling children within the school system, to what this can be attributed, the cultural stigmas, where social workers and other mental health professionals can be helpful and suggestions for further research.

\section{Literature review}

A review of the literature suggests that there are unique needs, weaknesses and strengths to the Orthodox Jewish community in terms of its response to the emotional/behavioral needs of children in the school system. These findings suggest that social work-teacher collaboration may be a successful area in which to properly and successfully assist these children.

Yeung and Greenwald [4] conducted a review of the National Institute of Mental Health (NIMH) Epidemiological Catchment Area (ECA) study to determine the rates of psychopathological disorders and help-seeking behaviors amongst Jews as compared to non-Jews. The sample of this study was drawn from the NIMH ECA program which studied the rates and risks for psychiatric disorders drawn from a probability sample of over 18,000 adults living in 5 U.S. cities. New Haven, Connecticut was the only city to ask in their survey for religious preference and was the basis for this study. Analysis was conducted to determine the strength of the association between religious preference and outcome variables. Odds ratios with a confidence ratio greater than 1 represented a statistical significance. Results showed that Jews

Correspondence to: E. Dovid Bak, Lakewood Community Services Corp., USA, E-mail: Dovidbak@gmail.com

Received: July 08, 2015; Accepted: November 09, 2015; Published: November 12,2015 
had higher rates of major depression, schizophrenia, and simple phobia than for Catholics and Protestants. Rates of alcohol abuse were lower. There was no statistical significant difference when comparing bipolar disorder, panic disorder, agoraphobia, social phobia, obsessivecompulsive disorder, and drug abuse. Overall lifetime rates of psychopathology were not higher for Jews.

As stated earlier there are many subgroups to Judaism and although these results may be indicative of Jews in general, it is important to see if this would be substantiated amongst Orthodox Jews.

Lindsey et al. [5] conducted a study of 262 children in the Orthodox Jewish community of London. The purpose of the study was to determine the prevalence of psychopathology within this specific group. Five nursery schools agreed to participate in the study. One hundred seventy of the children (69\%) were girls and 67 (28\%) boys; the remaining seven questionnaires were unclear. Sixty-one percent of children for whom age data were available $(N=236)$ were threeyear-olds, and $39 \%$ were four-year-olds. About $54 \%$ of the sample had recognizable financial difficulties. Family size was large with a mean of 5.4 children per family. Due to the fact that the authors were studying 3-4-year-olds, this meant that most children had several older brothers and sisters. Teachers were asked to complete the Strengths and Difficulties Questionnaire (SDQ), teachers' version. Parents completed the SDQ, parents' version and both groups completed a background characteristic form. The SDQ is well validated and measures emotional, conduct, hyperactivity and peer disorders and prosocial abilities. Results show that teachers were more likely than parents to rate these children as having difficulties, particularly of the hyperactivity kind. Correlation between teachers' and parents' ratings were significant for hyperactivity, peer relations, and prosocial behavior $(p<.001)$. Additionally, boys were found to be rated higher in conduct problems as reported by parents with the results being statistically significant $(p<.05)$. A regression analysis was conducted in order to determine the predictive power of some of the background factors. The results showed significantly that children who were perceived by teachers as to having, already at this young age, special needs were at a heightened risk in comparison to other children $(\mathrm{p}<.05)$

In a follow-up study, Frosh et al. [6] surveyed parents' and teachers' perceptions of the prevalence of emotional and behavioral disorders among children aged 5-15 amongst the Orthodox Jewish community of London. Parents and teachers of children in one class from each school year within each school were asked to complete the SDQ. Parents and teachers of 406 children were actually contacted, with completed questionnaires being received from parents of 226 children (56\%). Teacher data were initially obtained for all children (100\%) but parents opted to withdraw data for 37 children from the study, leaving 369 permissible teacher SDQs (91\%). This study followed the same format as their earlier study of preschool children with teachers and parents completing the SDQ and a background characteristics sheet. The authors noted that the lower economic status of this community would suggest that there might be high levels of childhood psychopathology. However, there were mitigating factors such as community cohesion and high levels of community and family support. The purpose of this study was to determine the prevalence rates for teacher- and parent-rated emotional and behavioral difficulties among children aged 5-14 years, the effects of age and gender, predictive factors relating to emotional and behavioral difficulties, and if protective factors operating within this community are a factor in maintaining lower rates. Results showed that rates were similar to those found in the general population. One exception was the high rate of pro-social difficulties amongst older boys as rated by the teachers. Teachers' and parents' ratings of emotional difficulties and hyperactivity were similar to each other, however, parents' ratings of conduct problems were higher than teachers' ratings $(p<.01)$, and teachers' ratings of peer relationship and pro-social behavior difficulties were higher than parents' ratings $(p<.001)$. The authors note that this does not appear to show any systematic relationship between parents and teachers regarding children's perceived difficulties. Jewish children were generally seen as less disturbed than the national sample on most measures, though the older boys were rated higher by teachers on some measures, than were older boys in the national sample $(p<.001)$. Regression analysis was conducted to determine predictive power of these ratings. A very significant predictor of teacher rated difficulties was children who had special education needs. These included: Physical disabilities, illness, attention or motivation difficulties, and cognitive or speech impairment.

Overall high rates of emotional difficulties were not found. Parents rated their children lower than the national average and teachers' ratings were similar to the national samples with the one notable exception of higher reporting of older boys' difficulties on some measures. The authors note that when comparing this sample with similar innercity samples with lower socio-economic status and large family size, the findings actually suggest lower rates of psychopathology. This may indicate that the presence of marital stability, a high degree of social and family cohesion, and support.

However, as mentioned earlier therapeutic intervention in the Orthodox Jewish community has its particular challenges and implementing new approaches would surely meet some resistance. Feinberg and Feinberg [7] conducted a 1984 survey of Orthodox mental health professional to assess whether the Orthodox Jewish community is being undeserved and how to address their needs. An eighteen question survey was completed by 70 Orthodox mental health professionals recruited through the Association of Orthodox Jewish Scientists' (AOJS) Behavioral Science/Mental Health Section. The most common problems that led to patients seeking counseling were marital and family problems (62\%), significant personality disorders (53\%), and Schizophrenia (51\%). Eighty nine percent of the respondents felt that the mental health needs of the Orthodox Jewish community were somewhat underserved with $40 \%$ feeling that the needs were significantly underserved. When compared to other groups $73.9 \%$ felt that the Orthodox were more poorly served with most respondents (82\%) feeling that the Ultra-Orthodox was the subgroup most in need of additional services. Regarding possible factors for this trend, 58\% felt that stigma (personal or family) was the most important reason, and $94 \%$ felt it was somewhat pertinent. Furthermore, $82 \%$ felt there would be a benefit for clinics to be located in areas other than in the heart of the community.

In an unpublished study, Schnall [8] conducted a follow-up survey of Orthodox Jewish mental health professionals to determine the most prevalent psychological disorders within the Orthodox Jewish community, how well each segment of the community is being served, and how much stigma is still associated with mental health conditions. This study was a follow-up to the Feinberg and Feinberg study [9]. Responding clinicians who felt members mistrust of the mental health field dropped from 87 to 59 percent; stigmatization fell from 93 to 70 percent; and mental health being unaffordable from 57 percent to 47 percent. Forty-eight percent of respondents felt that the UltraOrthodox are underserved, however that number rises to 58 percent when asked about the Chasidim. 
Schnall [10] points to a number of institutional barriers that make it difficult for the Orthodox Jew to accept counseling. To many Orthodox Jews the fact that therapists are university educated contributes to this problem. There are many who view these educated professionals as an extension of the secular world which they strive to avoid. Additionally, they may be wary that the therapist may attempt to dissuade them from their religious beliefs. There also exists a fear that the professional will be quick to report problems to governmental authorities. It must be noted that the inbred fear of outsiders, a result of years of persecution, has caused the Jew to be wary of outsiders.

Many Orthodox Jews are also very concerned about the stigma attached to seeking psychological help. This is compounded by the fact that most marriages are arranged and that much importance is placed upon family background. If information about an immediate family member needing psychiatric counseling were to become public, it may ruin chances of another family member attaining a suitable match. This was further corroborated by Pirutinsky et al. [3] who conducted a study to determine if mental illness stigma is decreasing among Orthodox Jews. Ninety one Orthodox Jews participated in a study which surveyed attitudes towards mental illness. Participants were given a case vignette describing an individual with Obsessive Compulsive Disorder (OCD) and were then surveyed. The results showed that when believing that mental illness is a genetic problem the rate of stigma increased significantly $(p<.05)$ particularly in the area of family/marriage stigma. This led the authors to conclude that "a biomedical approach favoring professional treatment may serve to increase key culture-specific aspects of stigma among Orthodox Jews" (p. 511).

Generally, in Orthodox Jewish community life members will turn first to a Rabbi before seeking counseling. Schnall quotes a survey by Wikler [11], which found that there were very few instances in which Orthodox Jews in therapy had been sent by their rabbis. However as mentioned earlier there is reason to believe this may be changing. Loewenthal [12] further identified the main barriers within the orthodox Jewish community against seeking help for psychiatric problems. In many areas she is in consonance with Schnall [10] stating that the main barriers are: stigma, concerns about violating Jewish religious law, and perceived conflicts between values inherent in psychotherapy and Jewish values. Accordingly, many rabbis are overwhelmed with pastoral and counseling work and would refer to professional help. She notes that there is community and rabbinic support for the provision of religiously-appropriate psychological and psychiatric services in almost all orthodox Jewish communities. In actuality Loewenthal [12] found that the Orthodox Jew uses the following methods for mental health help: Prayer, Rabbis, statutory services (where they can remain anonymous), culture-sensitive services (but from dissimilar religious/ cultural background) and own-group counselors (but from outside one's own immediate community).

Clearly there are many issues that are preventing the mental health profession from assisting the community at large. Yet there are hopeful signs that those barriers are beginning to thaw. As such, the question this study attempted to answer was: What are the perceptions of teachers in Orthodox Jewish schools of needs and causes of struggling students? The hypothesis is that many difficulties with functioning are not being recognized at an early age and that even when noticed are not being adequately addressed.

\section{Method}

This is a descriptive, quantitative study with 17 subjects. Given the nature of the community, a purposive, non-probability sampling method was used to collect subjects. The sample consisted of both male and female teachers who were either Judaic or secular in their religious orientation.

The data gathering mechanism used was a five point Likert scale instrument that was designed in response to the sensibilities of the Orthodox community. The instrument was comprised of 29 questions divided into 3 sections. Question 1, secured the participants consent, Questions 2 thru 12 were attribute questions and Questions 13 thru 29 which took the form of a five point Likert scale, measured teacher's attitudes.

On the gender and marital questions responses to the questionnaire were revised to reflect cultural sensitivity. Choices on gender (e.g. other) and marital status (e.g. common law) that are not reflective of the values of the community would be viewed negatively by respondents in this community and would harmfully impact participation. On the question of employment the instrument listed the main areas of employment with the additional option of "studying in Kollel (married Judaic studies program)". The rationale behind this is that in the community, learning in Kollel is not considered unemployment; rather the dedication to further studies is considered a lofty goal.

In determining the validity of this survey, face and content validity were used. In designing the survey this author used his experiences within the Jewish community and the academic field. Additionally, 3 principals were interviewed to determine their perceptions of areas of concern. Nevertheless, the sampling size itself and the inability to further test the validity of this measure with other criterion (e.g. known groups) is a limitation in this study [13].

Threats to reliability also exist. Ideally in order to test survey reliability over time, a test-retest study should be administered prior to using the survey [13]. However, constraints of time and resources made this prohibitive.

\section{Results}

Of the attributed reasons for students' struggling (see Attachment A) the most dominant responses were: lack of coping skills ("somewhat" $64 \%$ ), poor parenting ("possibly" $47 \%$ ), inborn personality ("somewhat" $60 \%$ ), and academic weakness ("somewhat" 53\%). Bullying, peer pressure and child abuse did not appear to be major factors from the teachers' perspectives.

While the instrument did not include any explicit questions about respondents level of understanding and attitude towards well documented mental health/ illness issues such as the effects of bullying and abuse, especially among children of this age, attributing the behavioral problems to poor parenting, the lack of coping skills and inborn personality traits is inconsistent with national trends that recognize these behaviors as often the result of bullying and abuse. Conversely, the behaviors of the children that were evaluated and reported on by the teachers in this study were consistent with national trends of children who were bullied or abused. These mental health/ illnesses included, but were not limited to, anxiety, depression, social withdrawal, disruptive and aggressive behaviors.

Moreover, attributing behavioral problems to poor parenting, poor coping skills and intrinsic personality, ironically all of which are mental health issues, further suggest the low level of awareness or willingness to embrace contemporary concepts of mental illness among the teachers in the study.

The failure to recognize abnormal levels of depression, anxiety, 
social withdrawal, marked reduction in academic and social functioning, and disturbance of conduct as symptoms of mental health issues supports the hypothesis.

\section{Discussion}

Seventy-three percent of the teachers have class sizes with more than 25 students. Of these, more than $46 \%$ reported that $11-20 \%$ of students were struggling. This computes to approximately 4-5 students per class. In a typical school in the surveyed area there are 3 parallel classes which would amount to 12-15 struggling students per grade. Generalized over an entire school this would indicate an extremely unfortunate amount of students who struggle daily in school.

As stated earlier the most dominant responses for students' struggling were: lack of coping skills, poor parenting, inborn personality, and academic weakness. Bullying, peer pressure and child abuse did not appear to be major factors from the teachers' perspectives. This is in stark contrast to reported statistics nationwide. Nansel et al. [14] found that 17 percent of students reported having been bullied at least "sometimes" during the school term and 8 percent had been bullied at least once a week. According to the U.S. Department of Health and Human Services (2010) [15] they were 10.1 reported cases of child abuse and neglect per 1000 children nationally. Additionally, Finkelhor et al. [16] estimated that 1 in 5 children in the United States experience some form of abuse and/or neglect. While it is possible that amongst the Jewish Orthodox community the numbers may be lower than the national average, it is equally possible that there are other factors that may be affecting the possible underreporting. It must be further noted that in addition to the statistical significance (see Attachment B) between teacher's gender and attribution of students struggling $(p<.05)$, the female teachers all reported a "possible" or "somewhat" attribution of child abuse while $53 \%$ of the men reported "definitely not". Furthermore, although teacher's gender was not statistically significant in relation to their perceptions of students struggles, nevertheless as noted earlier $53 \%$ of the male respondents reported having between $11-20 \%$ of students struggling, while the female teachers reported only $0-10 \%$ of students are struggling.

There may be a number of factors that contribute to this trend. Generally, male Judaic studies teachers have limited training before they enter the field of education. Most have spent a number of years studying the Talmud and have attained a high degree of proficiency in their studies. During this time, while their husbands are immersed in their studies, it is not uncommon for the women to be the main providers in the home. Thus, many women teachers are college graduates or have had formal training. The men have none, or very limited, formal preparation for teaching and although many male teachers in the Orthodox Jewish community do take a yearlong training, nevertheless, in discussions with the teachers most acknowledged that they were not fully prepared for the experience of teaching which includes classroom management, methods, and understanding children. This lack of appropriate preparation may be a part explanation for their attribution of students' struggles to poor parenting rather than to abuse and bullying.

Additionally, the lack of formal training may be contributing to a lower sense of self-efficacy towards teaching which may be impacting the classroom. Weisel and Dror [17] examined Israeli teachers' attitude towards inclusion of students with special needs and the relationship between the school climate, and teachers' sense of self efficacy. Results of the study showed that sense of efficacy, and especially self-efficacy, contribute the most in explaining the variance of attitudes towards inclusion $(p<.05)$. This was shown to have greater impact than seniority, special education training, and school climate. While we acknowledge that special education is different than psychopathology, nevertheless, the teachers' sense of self-efficacy may be an important criterion in their ability to help these children.

There also is the aforementioned stigma which not only prevents the seeking out of help but may additionally not allow the community to see the struggles as psychopathology, instead attributing the struggles of a child to the more discernable poor parenting. Although a large percentage of the teachers acknowledged the benefits of having a social worker on staff and it is the experiences of this author that teachers generally do welcome the involvement of the social worker, however the low level of attribution to areas that have generally been reported at higher levels nationwide is an area that further research should tackle.

\section{Implications}

The answer to these concerns of stigma, teachers' lack of understanding of children and psychopathology, might be to incorporate more social workers into the Orthodox Jewish school system. With their professional insight, access to a wide range of treatment models, and an appreciation of interdisciplinary collaboration, they would be best poised to assist these troubled children.

Additionally, by collaborating with teachers, giving teachers a greater sense of self-efficacy and creating a positive school climate geared towards helping each individual we may be able to reduce levels of stigma and make mental health services more available to children.

According to Weisel and Dror [17] teachers exhibiting a high sense of self efficacy, who tend to attend training in matters related to special education, and who are employed in schools that have supportive leadership that encourages autonomy and renovation, are those who demonstrate more positive attitudes toward inclusion. This was further substantiated by Lynn et al. [18] who determined that proactive teacher classroom practices have been associated with reduced child behavioral problems and increased academic engagement. They found that there is strong evidence that the development of teacher-social worker collaboration was helpful in developing intervention strategies for meeting the mental health needs of students. This collaboration included establishing a positive atmosphere in which everyone understands that all have a common interest in working together and regular meetings with teachers to ensure consistent contact and communication.

One particular model which has shown some success is the Social worker-teacher collaboration (SWTCC) model. In 2001, Viggianni et al. [19] conducted a study of the SWTCC model to determine if the intervention was successful in improving attendance, classroom behavior and grades. This model requires the social work intern to be responsible for intervening with behavioral and attendance issues, whereas the teacher focused on teaching academic materials. There are weekly collaborative meetings which facilitate ongoing communication between the teacher and the social worker which helps the collaborative team implement task-centered methods in a structured and efficient manner. The sample consisted of four classrooms (two kindergartens and two third grades) in an elementary school located in an impoverished neighborhood in Albany, New York. SWTCC was implemented in one of the kindergartens and in one of the third-grade classrooms. The comparison classrooms did not receive SWTCC but could refer students to a social worker. 


\section{Limitations}

This study has a number of limitations. Small sample size, the inclusion of only one school, a small number of women teachers were all limitations which should be addressed in future research. As stated early there exists threats to reliability which further testing should address. Additionally, as reports of struggling children tend to rise as the year progresses, a test-retest should be administered to gauge teachers' true perceptions of their students.

\section{Conclusion}

The present study was conducted to determine teachers' perception of struggling student in their classroom within one Orthodox Jewish community. Majority of respondents reported that between 11$20 \%$ of their students were struggling. They attributed this more to poor parenting and inborn personality than to bullying and abuse. Although these numbers may be accurate and representative of the Orthodox Jewish community, nevertheless they are markedly lower than the national averages. As a result further research should be conducted to determine the reasons for this disparity. Possible reasons for underreporting may be the male teachers' lack of preparation and training in child education and stigma where it is difficult to accept that these problems exist and/or an unwillingness to seek remediation. Potential solutions would include the development, with input from school administrators, teachers and social workers, of a comprehensive teacher-training program. This intensive training would go beyond classroom management and teaching methods. Its focus would be to educate teachers in child development, and a basic understanding of child psychopathology.

Additional recommended solutions were to developing schools strong social work-teacher collaboration programs, where teachers do not feel threatened by the worker and are encouraged to be a part of the process. With the further implementation of successful collaborative programs throughout the community we can hope to reduce the number of struggling students and lessen the cultural stigma towards mental health both for the educational community, parents and hopefully the community at large.

\section{References}

1. U.S. Department Of Health And Human Services (1999). Mental health: A report of the Surgeon General. Bethesda, MD: US Department of Health and Human Services.

2. Pescosolido BA, Martin JK, Long JS, Medina TR, Phelan JC, et al. (2010) “A disease like any other"? A decade of change in public reactions to schizophrenia, depression, and alcohol dependence. Am J Psychiatry 167: 1321-1330. [Crossref]
3. Pirutinsky S, Rosen DD, Shapiro Safran R, Rosmarin DH (2010) Do medical models of mental illness relate to increased or decreased stigmatization of mental illness among orthodox Jews? J Nerv Ment Dis 198: 508-512.[Crossref]

4. Yeung PP, Greenwald S (1992) Jewish Americans and mental health: results of the NIMH Epidemiologic Catchment Area Study. Soc Psychiatry PsychiatrEpidemiol 27: 292-297.[Crossref]

5. Lindsey C, Frosh S, Loewenthal K, Spitzer E (2003) Prevalence of emotional and behavioural disorders among strictly orthodox Jewish pre-school children in London. Clin Child Psychol Psychiatry 8: 459-472.

6. Frosh S, Loewenthal K, Lindsey C, Spitzer E (2005) Prevalence of emotional and behavioural disorders among strictly Orthodox Jewish children in London. Clin Child Psychol Psychiatry 10: 351-368.

7. Feinberg SS, Feinberg KG (1985)An assessment of the mental health needs of the Orthodox Jewish population of metropolitan New York. Journal of Jewish Communal Service 62: 29-39.

8. Schnall E (2010) Psychological disorder and stigma: A 25-year follow-up study in the Orthodox Jewish community. Paper presented at the American Psychological Association. San Diego, CA.

9. The Jewish Week (2010, August 17). Orthodox mental health needs not being met: Study. Retrieved February 3, 2011, from http://www.thejewishweek.com/news/new york/orthodox_mental_health_needs_not_being_met_study

10. Schnall E (2006) Multicultural counseling and the orthodox Jew. American Counseling Association 84: 276-282.

11. Wikler M (1986) Pathways to treatment: How Orthodox Jews enter therapy. Social Casework 67: 113-118.

12. Lowenthal KM (2006)Strictly orthodox Jews and their relations with psychotherapy and psychiatry. World Cultural Psychiatry Research Review 1: 128-132.

13. Salkind N (2008) Statistics for people who (think they) hate statistics (3rdedn), Thousand Oaks, Calif.: Sage Publications.

14. Nansel TR, Overpeck M, Pilla RS, Ruan WJ, Simons-Morton B, et al. (2001) Bullying behaviors among US youth: Prevalence and association with psychological ajustment. JAMA 285: 2094-2100

15. U.S. Department Of Health and Human Services (2010) Child maltreatment 2009. Author.

16. Finkelhor D, Turner H, Ormrod R, Hamby SL (2009) Violence, abuse, and crime exposure in a national sample of children and youth. Pediatrics 124: 1411-1423. [Crossref]

17. Weisel A, Dror O (2006) School climate, sense of efficacy and Israeli teachers' attitudes toward inclusion of students with special needs. Education, Citizenship and Social Justice 1: 157-174. [Crossref]

18. Lynn CJ, McKernan-McKay M, Atkins MS (2003) School social work: Meeting the mental health needs of students through collaboration with teachers. Children and Schools 25: 197-209.

19. Viggianni PA, Reid WJ, Bailey-Dempsey C (2002) Social worker-teacher collaboration in the classroom: Help for elementary students at risk of failure. Research on Social Work 12: 604-620.

Copyright: (C2015 Liebowitz J. This is an open-access article distributed under the terms of the Creative Commons Attribution License, which permits unrestricted use, distribution, and reproduction in any medium, provided the original author and source are credited. 